Sharif University of Technology
Scientia Iranica
Transactions E: Industrial Engineering
wCIENTIA

\title{
A novel grey target decision-making model based on cobweb area and its application for choosing the software development pattern
}

\author{
B. Zeng ${ }^{\mathrm{a}, \mathrm{b}}$, Ch. Li ${ }^{\mathrm{c}, *}$ and S.-F. Liu ${ }^{\mathrm{d}}$ \\ a. School of Business Planning, Chongqing Technology and Business University, Chongqing 400067, China. \\ b. School of Management and Economics, University of Electronic Science and Technology, Chengdu 611731, China. \\ c. Engineering Laboratory for Detection Control, Chongqing Technology and Business University, Chongqing 400067, China. \\ d. School of Management and Economics, Nanjing University of Aeronautics and Astronautics, Nanjing 210016, China.
}

Received 17 May 2014; received in revised form 2 December 2014; accepted 25 January 2015

\section{KEYWORDS \\ Grey target decision- making model; Magnification or reduction effect; Cobweb area; Selection of software development pattern.}

\begin{abstract}
A grey target decision-making model is an effective method used to look for a relatively optimal decision-making scheme. In this method, whether a scheme is good or bad is determined through comparing the square sums of the differences between the evaluated indices and the optimal indices. However, such "power operation" probably results in amplification or reduction of some extreme index values in decision-making results. In this paper, an improved method, based on cobweb area, is proposed. Here, an index is represented by a line drawn from the bull's-eye, with equal angles between adjacent lines. Then, data points are determined on the lines so that the length of a line segment represents the size of the index value. Each point is then connected in order, and a cobweb-like geometrical figure is obtained. With the proposed figure, each scheme could be evaluated by finding the area of its corresponding cobweb. The proposed model was applied in choosing the preferred software development mode of the Chana Group Office Automation system, and its performance was then compared with that of the traditional grey target decision-making model. The comparison shows that the new model is superior to the traditional grey target model.

(C) 2016 Sharif University of Technology. All rights reserved.
\end{abstract}

\section{Introduction}

The grey decision-making model is an important constituent of Grey System theory established by Deng [1$2]$ in 1982. After more than 30 years of development, it has become one of the main methods dealing with uncertainty decision problems [3-5], and is widely used in petroleum development, system evaluation, military decision-making, energy and building, and other application areas [6-10]. The main concern of the grey target decision-making model is to choose the optimal indices,

*. Corresponding author.

E-mail addresses: zbljh2@163.com (B. Zeng);

lcctbu@126.com (Ch.Li); sfliu@nuaa.edu.cn (S.-F.Liu) which will be set as the multidimensional bull's-eye. Consequently, one can calculate the distances between the corresponding index values of each scheme and the bull's-eye. Finally, by comparing the distances from the bull's-eye, one can determine the relatively optimal scheme. Usually, the closer the indices are to the bull'seye, the better the scheme is [11].

Initially, the grey target decision-making model was not perfect. Hence, much research focused on how to optimize the modeling method and extend the model's application scope. Liu et al. [12] designed the critical value of the grey target as the dividing point of positive and negative values, which is known as the zero point. Two cases of whether or not the objective effect value hit the bull's-eye were fully considered. As a 
result, they proposed a multi-attribute intelligent grey target decision-making model. Wang et al. [13] took into account the correlation between different indices, as well as the influence of both different dimensions, and the importance of each index on the effect of decisions. Thus, the traditional grey target modeling method was improved using the approach of weighted Mahalanobis distance. Hua and Tian [14] constructed a grey target decision model regarding optimization of a variety of mutually exclusive schemes. This improves the accuracy and objectivity of traditional decisionmaking. Considering the fact that the decision-making process should take into account weightings not only of indices, but also of decision-makers, Zeng and Liu [15] proposed a new concept, named the twiceweighted grey target decision model. Moreover, some researchers [16-21] built a novel grey target decisionmaking model based on interval number, and their research findings extended the modeling objects from real numbers to interval numbers. Also, other scholars studied a combination of decision-making models using the grey target model and other methods [22-25], such as the Analytic Hierarchy Process (AHP), and Data Envelopment Analysis (DEA).

The above research findings, however, acquired bull's-eye distances through calculating the square sums of the differences between the decision indices of each scheme and the optimal indices. It is noted that computing methods based on square operations may result in the "amplification effect" of some secondary indices' maximums or the "reduction effect" of some important indices' minimums. As a result, the magnitude of the bull's-eye distance cannot be used to represent or judge if a scheme is good or bad. For this reason, the grey target decision-making model is not suitable for use in choosing a satisfactory scheme.

In this paper, a novel grey target decision-making model based on cobweb area was proposed, taking into consideration modeling methods in literature $[26,27]$. The proposed model avoids the effects of magnification or reduction of square operations in the traditional grey target decision-making method. It can be used to choose a relatively optimal scheme by calculating the cobweb area encircled between the decision-making indices and the optimal indices. This new method reduces the effect of traditional square arithmetic in the grey target decision model on the result of decision making, and is a significant improvement on optimization of the grey target modeling method.

This paper is organized as follows. In Section 2, some basic knowledge of the grey target decisionmaking model is introduced. Our novel grey target model, based on cobweb area, is put forward in Section 3. In Section 4, the proposed decision-making model is employed to choose a relatively reasonable software development model for the Chana Group
Office Automation (OA) system. Comparison with a traditional decision-making method is also presented in this section. Conclusions are given in Section 5 .

\section{Basic concepts}

\subsection{Primary concepts [28]}

Definition 2.1. The totality of all events within a range of research is called the set of events of the research, denoted as:

$$
A=\left\{a_{1}, a_{2}, \cdots, a_{n}\right\},
$$

where $a_{i}, i=1,2, \cdots, n$, is the $i$ th event. The corresponding totality of all possible countermeasures is called the countermeasure set, which is defined as:

$$
B=\left\{b_{1}, b_{2}, \cdots, b_{m}\right\}
$$

where $b_{j}, j=1,2, \cdots, m$, is the $j$ th countermeasure.

Definition 2.2. According to Definition 2.1, assuming that $A$ is the set of events of research and $B$ is the countermeasure set, the Cartesian product is given by:

$$
A \times B=\left\{\left(a_{i}, b_{j}\right) \mid a_{i} \in A, b_{j} \in B\right\} .
$$

It is called the situation set, as denoted by $S=A \times B$. For any $a_{i} \in A$ and $b_{j} \in B$, the pair $\left(a_{i}, b_{j}\right)$ is called a situation, which is denoted by $s_{i j}=\left(a_{i}, b_{j}\right)$.

Definition 2.3. The totality of all objectives within a range of research is the set of objectives of the research, i.e.:

$$
K=\left\{k_{1}, k_{2}, \cdots, k_{t}\right\},
$$

where $k_{h}, h=1,2, \cdots, t$, is the $h$ th objective.

Definition 2.4. Suppose $S=\left\{s_{i j}=\left(a_{i}, b_{j}\right) \mid a_{i} \in\right.$ $\left.A, b_{j} \in B\right\}$ is the situation set, and $u_{i j}^{\left(k_{h}\right)}$ is the effect value of situation $s_{i j}$, with objective $k_{h}$, and $R$ being the set of all real numbers. One has:

$$
u^{\left(k_{h}\right)}: S \rightarrow R, \quad s_{i j} \mapsto u_{i j}^{\left(k_{h}\right)} .
$$

It is called the effect mapping of $S$, with the objective $k_{h}$.

Definition 2.5. Events, countermeasures, objectives and effects are the four elements of decision-making.

Grey target decision-making model [20]. $S=$ $\left\{s_{i j}=\left(a_{i}, b_{j}\right) \mid a_{i} \in A, b_{j} \in B\right\}$ represents the situation set and $K=\left\{k_{1}, k_{2}, \cdots, k_{t}\right\}$ stands for the objective set. All effect values of situation $s_{i j}$ with objective set $K$ are given by:

$$
s_{i j} \mapsto u_{i j}=\left(u_{i j}^{\left(k_{1}\right)}, u_{i j}^{\left(k_{2}\right)}, \cdots, u_{i j}^{\left(k_{t}\right)}\right) .
$$


In the process of decision-making, firstly, we need to set the optimal value for each objective, and those values constitute the optimal effect vector, $u_{o}$, i.e.:

$$
u_{o}=\left(u_{o}^{\left(k_{1}\right)}, u_{o}^{\left(k_{2}\right)}, \cdots, u_{o}^{\left(k_{t}\right)}\right)
$$

$u_{o}$ is called the multidimensional bull's-eye; it represents the ideal optimal values of all objectives. Moreover, one has:

$$
d_{i j}^{(h)}=\left|u_{i j}^{\left(k_{h}\right)}-u_{o}^{\left(k_{h}\right)}\right|
$$

It is called the distance of situation, $s_{i j}$, with optimal objective $k_{h}$.

Definition 2.6. Let $r_{i j}^{(1)}, r_{i j}^{(2)}, \cdots, r_{i j}^{(t)}$ represent the threshold values of situation $s_{i j}$, with objective $1,2, \ldots$, $t$, respectively, the following region of $t$-dimensional space:

$$
\begin{gathered}
S_{i j}^{t}=\left\{d_{i j}^{(1)}, d_{i j}^{(2)}, \cdots, d_{i j}^{(t)} \mid d_{i j}^{(1)} \leq r_{i j}^{(1)}, d_{i j}^{(2)}\right. \\
\left.\leq r_{i j}^{(2)}, \cdots, d_{i j}^{(t)} \leq r_{i j}^{(t)}\right\}
\end{gathered}
$$

is said to be a desirable situation, and $b_{j}$ a desirable countermeasure of event $a_{i}$, with objective $1,2, \cdots, t$.

The grey target is essentially the region for location of the desirable effect in terms of relative optimization. In many cases, since achieving the absolute optimum is often impossible, reaching a suboptimal result is also accepted as satisfactory for some cases. Of course, according to the requirement of need, we can gradually refrain from stopping the shrinking of the grey target for decision-making, until it degenerates into the bull's-eye, which is the optimum effect, with the corresponding situation as the optimum situation, and the corresponding countermeasure as the optimum countermeasure.

Definition 2.7. In the premise of satisfying Definition 2.6, the following;

$$
\begin{aligned}
& d_{i j}= \\
& \sqrt{\left(u_{i j}^{\left(k_{1}\right)}-u_{o}^{\left(k_{1}\right)}\right)^{2}+\left(u_{i j}^{\left(k_{2}\right)}-u_{o}^{\left(k_{2}\right)}\right)^{2}+\ldots+\left(u_{i j}^{\left(k_{t}\right)}-u_{o}^{\left(k_{t}\right)}\right)^{2}},
\end{aligned}
$$

is called the bull's-eye distance of situation $s_{i j}$, with objective set $K$ and bull's-eye, $u_{o}$.

Definition 2.8. Assume that $s_{i j}$ and $s_{p q}$ are different situations:

$$
s_{i j} \mapsto u_{i j}=\left(u_{i j}^{\left(k_{1}\right)}, u_{i j}^{\left(k_{2}\right)}, \cdots, u_{i j}^{\left(k_{t}\right)}\right),
$$

and:

$$
s_{p q} \mapsto u_{p q}=\left(u_{p q}^{\left(k_{1}\right)}, u_{p q}^{\left(k_{2}\right)}, \cdots, u_{p q}^{\left(k_{t}\right)}\right),
$$

are the effect vectors, respectively. If:

$$
d_{i j} \leq d_{p q}
$$

then, situation $s_{i j}$ is said to be superior to situation $s_{p q}$, i.e. $s_{i j} \succ s_{p q}$. When an equal sign holds true here, situation $s_{i j}$ and $s_{p q}$ are said to be equivalent, denoted as $s_{i j} \cong s_{p q}$.

\section{The proposed grey target decision-making model}

\subsection{Limitation of traditional grey target decision-making model}

In the following paragraphs, the limitation of the traditional grey target model is illustrated using an example. Assume that $s_{11}$ and $s_{12}$ are different situations, their effect vectors are as follows:

$$
\begin{aligned}
s_{11} \mapsto u_{11} & =\left(u_{11}^{\left(k_{1}\right)}, u_{11}^{\left(k_{2}\right)}, u_{11}^{\left(k_{3}\right)}, u_{11}^{\left(k_{4}\right)}, u_{11}^{\left(k_{5}\right)}\right) \\
& =(9,9,8,8,6),
\end{aligned}
$$

and:

$$
\begin{aligned}
s_{12} \mapsto u_{12} & =\left(u_{12}^{\left(k_{1}\right)}, u_{12}^{\left(k_{2}\right)}, u_{12}^{\left(k_{3}\right)}, u_{12}^{\left(k_{4}\right)}, u_{12}^{\left(k_{5}\right)}\right) \\
& =(8,8,8,8,7) .
\end{aligned}
$$

The optimal effect vector (i.e., the bull's-eye) is:

$$
\begin{aligned}
u_{o} & =\left(u_{o}^{\left(k_{1}\right)}, u_{o}^{\left(k_{2}\right)}, u_{o}^{\left(k_{3}\right)}, u_{o}^{\left(k_{4}\right)}, u_{o}^{\left(k_{5}\right)}\right) \\
& =(10,10,10,10,10) .
\end{aligned}
$$

According to Definition 2.7, one can calculate the bull's-eye distance of situation $s_{11}$ and $s_{12}$ as follows:

$$
\begin{aligned}
& d_{11}=\sqrt{(9-10)^{2}+(9-10)^{2}+(8-10)^{2}+(8-10)^{2}+(6-10)^{2}} \\
& =\sqrt{26}, \\
& d_{12}=\sqrt{(8-10)^{2}+(8-10)^{2}+(8-10)^{2}+(8-10)^{2}+(7-10)^{2}} \\
& =\sqrt{25} .
\end{aligned}
$$

As given by Definition 2.8 , since $d_{11}>d_{12} \Rightarrow s_{11} \prec$ $s_{12}$, situation $s_{12}$ is superior to situation $s_{11}$. The fact, unfortunately, is just the opposite. Why is the result from the grey target decision-making model inconsistent with actual circumstances? The main reason is that the calculation process of the bull'seye distance amplifies or narrows the effects of extreme index values on decision results. To solve this problem, we propose a novel grey target decision-making model based on cobweb area to lessen the effects of extreme index values. This optimizes the calculation method of the original model and makes the decision results more reasonable. 


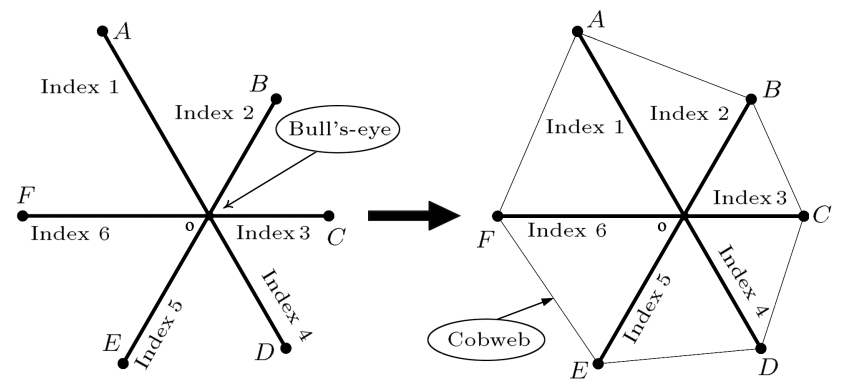

(a)

Figure 1. Formation of a cobweb based on index values of a scheme.

\subsection{Conformation of situation cobweb}

As shown in Figure 1(a), to construct a cobweb, the first step is to link each index value of a scheme with the bull's-eye (note: angles between adjacent lines are the same, and the length of a line segment represents the size of the index value). Each point is then connected in order $(A \rightarrow B \rightarrow C \rightarrow D \rightarrow E \rightarrow F)$. After that, a cobweb-like figure can be obtained (Figure 1(b)).

Calculation of the area of a scheme's cobweb is straightforward. As the size of cobweb area represents the proximity degree between the evaluated scheme and the optimal scheme, one can see that the smaller the area is, the better the scheme will be. A case study illustrated later in this paper shows that the present model is more reasonable than the traditional grey target decision-making model.

The cobweb proposed in this paper differs from the cobweb in the traditional economic field. It is composed of a bull's-eye and the index values of situations. Prior to research into a new decisionmaking model, we should first build the corresponding mapping relation between the bull's-eyes and the index values, as well as the cobweb figure. The drawing process of the cobweb is as follows:

1. Determine the optimal effect vector, $u_{o}$, and calculate the length vector, $L_{i j}$, of situation $s_{i j}$ with the optimal effect vector, $u_{o}$, (that is the bull's-eye). Suppose:

$$
u_{o}=\left(u_{o}^{\left(k_{1}\right)}, u_{o}^{\left(k_{2}\right)}, \cdots, u_{o}^{\left(k_{t}\right)}\right),
$$

and

$$
s_{i j} \mapsto u_{i j}=\left(u_{i j}^{\left(k_{1}\right)}, u_{i j}^{\left(k_{2}\right)}, \cdots, u_{i j}^{\left(k_{t}\right)}\right),
$$

then:

$$
L_{i j}=\left(l_{i j}(1), l_{i j}(2), \cdots, l_{i j}(t)\right),
$$

where:

$$
l_{i j}(h)=\left|u_{i j}^{\left(k_{h}\right)}-u_{o}^{\left(k_{h}\right)}\right|, \quad h=1,2, \cdots, t .
$$

The procedure is shown in Figure 2(a).

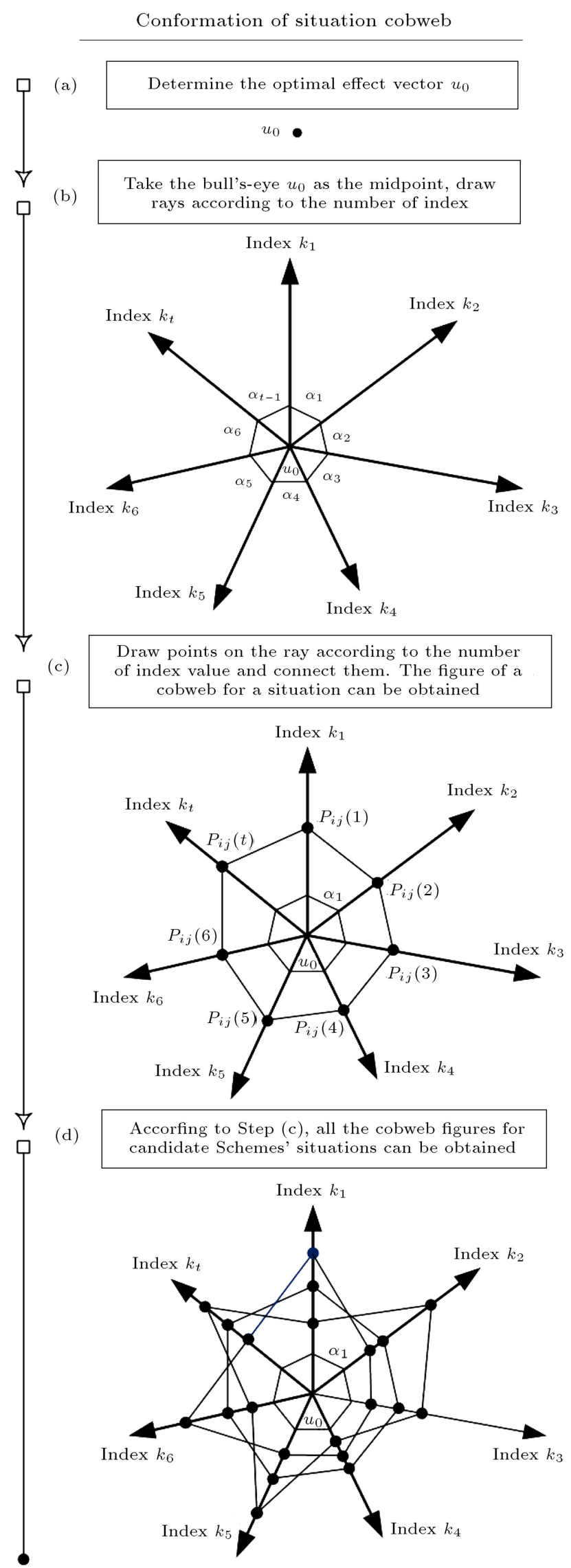

Figure 2. Procedure of establishing situation cobwebs. 
2. Take the bull's-eye, $u_{o}$, as the midpoint, and draw $t$ rays according to the number of index, $k_{t}$; angles between rays must be equal, say:

$$
\alpha_{1}=\alpha_{2}=\cdots \alpha_{t-1}=\frac{360^{\circ}}{t-1} .
$$

This procedure can be illustrated by Figure 2(b).

3. Draw point $P_{i j}(h)$ on the $h$-ray, on the basis of $l_{i j}(h)$ from the midpoint, $u_{o}$. Connect points $P_{i j}(1), P_{i j}(2), \cdots, P_{i j}(t)$ in sequence (i.e., $P_{i j}(1) \rightarrow$ $\left.P_{i j}(2) \rightarrow \cdots \rightarrow P_{i j}(t)\right)$. In this way, the figure of a cobweb for situation $s_{i j}$ can be obtained, as shown in Figure 2(c).

4. Following the same procedure, one can draw cobwebs of other situations. The result is shown in Figure 2(d).

\subsection{Derivation of the cobweb-based grey target decision-making model}

The cobweb area of situation $s_{i j}$ shows the proximity degree of vector $u_{i j}$ and bull's-eye $u_{o}$. So, the smaller the area is, the better the integral effect of a situation is. As a result, it can be used to evaluate the pros and cons of situations by comparing cobweb areas. To this end, we should first compute cobweb areas of situations. According to Figure 2, the cobweb's area coefficient, $v_{i j}$, of a situation, $s_{i j}$, can be computed as follows:

$$
\begin{aligned}
v_{i j}= & \frac{1}{2} \times\left|u_{i j}^{\left(k_{1}\right)}-u_{o}^{\left(k_{1}\right)}\right| \times\left|u_{i j}^{\left(k_{2}\right)}-u_{o}^{\left(k_{2}\right)}\right| \\
& \times \sin \frac{360^{\circ}}{t-1}+\rightarrow \frac{1}{2} \times\left|u_{i j}^{\left(k_{2}\right)}-u_{o}^{\left(k_{2}\right)}\right| \\
& \times\left|u_{i j}^{\left(k_{3}\right)}-u_{o}^{\left(k_{3}\right)}\right| \times \sin \frac{360^{\circ}}{t-1} \rightarrow+\cdots+\frac{1}{2} \\
& \times\left|u_{i j}^{\left(k_{t-1}\right)}-u_{o}^{\left(k_{t-1}\right)}\right| \times\left|u_{i j}^{\left(k_{t}\right)}-u_{o}^{\left(k_{t}\right)}\right| \\
& \times \sin \frac{360^{\circ}}{t-1} .
\end{aligned}
$$

So:

$$
\begin{aligned}
v_{i j}= & \frac{1}{2} \times\left[\left|u_{i j}^{\left(k_{1}\right)}-u_{o}^{\left(k_{1}\right)}\right| \times\left|u_{i j}^{\left(k_{2}\right)}-u_{o}^{\left(k_{2}\right)}\right|\right. \\
& \left.+\left|u_{i j}^{\left(k_{2}\right)}-u_{o}^{\left(k_{2}\right)}\right| \times\left|u_{i j}^{\left(k_{3}\right)}-u_{o}^{\left(k_{3}\right)}\right|+\cdots\right] \\
& \rightarrow\left[+\left|u_{i j}^{\left(k_{t-1}\right)}-u_{o}^{\left(k_{t-1}\right)}\right| \times\left|u_{i j}^{\left(k_{t}\right)}-u_{o}^{\left(k_{t}\right)}\right|\right] \\
& \times \sin \frac{360^{\circ}}{t-1} .
\end{aligned}
$$

For $l_{i j}(h)=\left|u_{i j}^{\left(k_{h}\right)}-u_{o}^{\left(k_{h}\right)}\right|,(h=1,2, \cdots, t)$, Eq.

$$
\begin{aligned}
v_{i j}= & \frac{1}{2}\left[l_{i j}(1) \times l_{i j}(2)+l_{i j}(2) \times l_{i j}(3)+\cdots\right. \\
& \left.+l_{i j}(t-1) \times l_{i j}(t)\right] \times \sin \frac{360^{\circ}}{t-1} .
\end{aligned}
$$

Finally, all situations should be sorted by the cobweb areas. If $v_{i j}<v_{p q}$, situation $s_{i j}$ is superior to situation $s_{p q}$, say, $s_{i j} \succ s_{p q}$. Eq. (2) or Eq. (3) can be named a multi-criteria cobweb grey target decision-making model, or a cobweb grey target model for short.

\section{Example study: mode selection of Office Automation (OA) system development}

\section{Example analysis I}

The Chang'an Automobile Group, commonly known as the Chana Group [29], is a giant, state-owned military industrial enterprise in China. Since 2000, corporate leaders have attached great importance to establishment of management informatization. Due to the enormous mechanism and complex process of management in the Chana Group, a common Office Automation (OA) system with a fixed process cannot adapt to its developmental needs. In such circumstances, the leaders of Chana proposed an idea of a self-defining workflow. As the workflow involves many complicated cutting-edge technologies, the IT department of Chana cannot accomplish the development of OA independently. On the other hand, the secrecy of the production process in a military industry means that risks exist if all the modules of OA are developed by external IT companies. Moreover, outsourcing of this nature hinders the technological improvement of the Chana Group. Hence, this is a multiple-target decision-making problem.

Software projects have special characteristics in comparison with ordinary projects [30]. Decisionmakers of an enterprise often choose different development modes according to different software projects. There are mainly four development modes for software projects: stand-alone development, joint development, portion outsourcing and overall outsourcing. Standalone development means that all the modules of a software project are accomplished by the enterprise's own human and material resources. Joint development means that software functions are completed by the enterprise with the help of other software companies. Portion outsourcing means that some of the modules of a software project are accomplished by other software companies. Last but not least, overall outsourcing means that all modules are completed by other software companies.

In this paper, we will employ the present cobwebbased grey target model to choose a relatively reasonable development mode for Chana's OA system. 
Modeling steps of development mode's selection for Chana's OA system

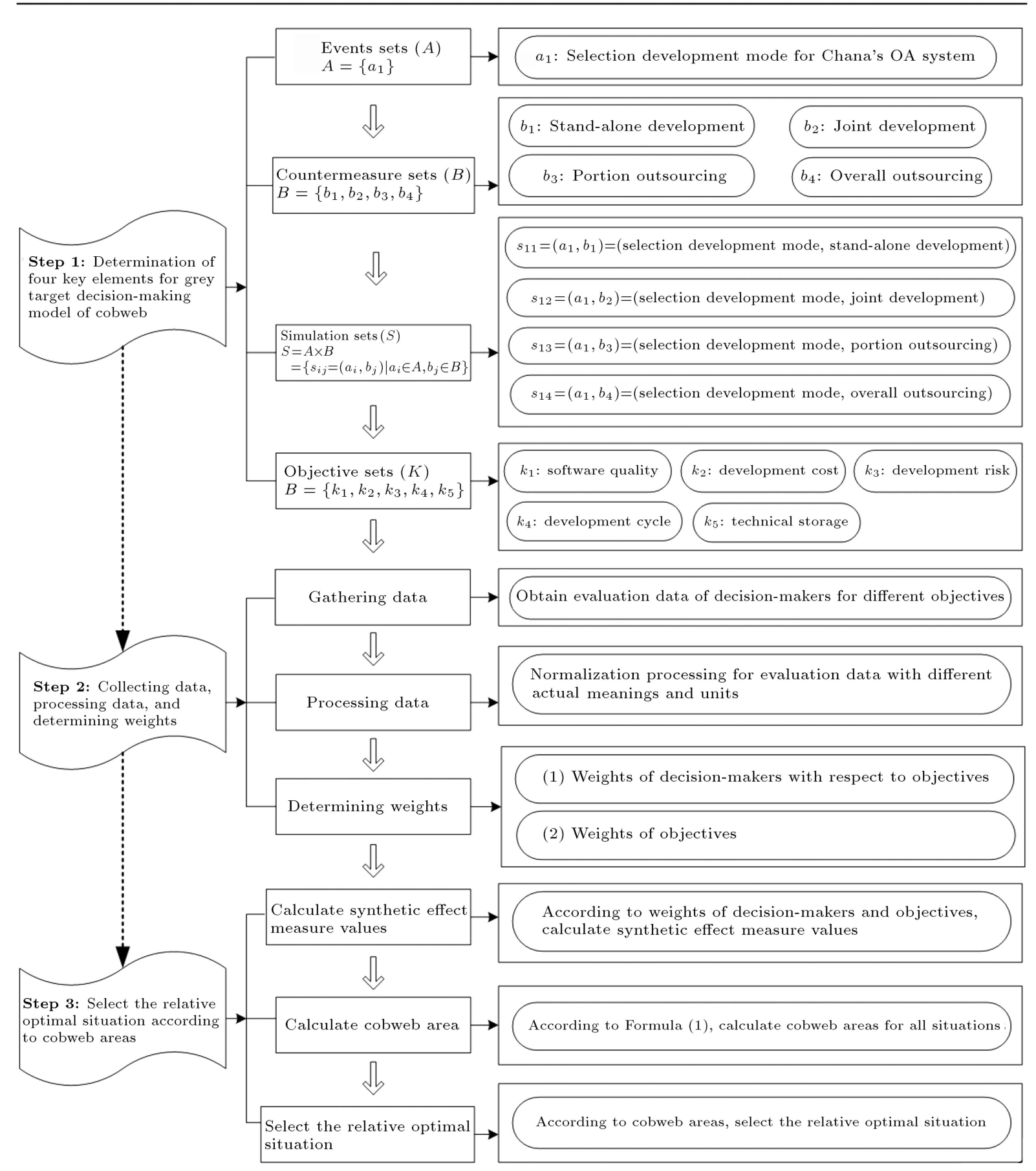

Figure 3. Modeling steps of development mode selection for Chana's OA system.

Figure 3 shows the modeling steps of the cobweb grey target model.

\subsection{Determination of four key elements for the cobweb grey target model}

According to Definitions 2.1-2.4 and information in Figure 3, four key elements of the cobweb based grey target model for Chana's OA system can be easily determined:
1. The set of events:

$$
\begin{aligned}
A=\left\{a_{1}\right\}= & \{\text { selection of the development mode } \\
& \text { for a software project }\} ;
\end{aligned}
$$

2. The countermeasure sets:

$B=\left\{b_{1}, b_{2}, b_{3}, b_{4}\right\}=\{$ stand-alone development of software, joint development of software, portion outsourcing of software and overall outsourcing of software\}; 
3. The situation set:

$$
A \times B=\left\{s_{i j}=\left(a_{i}, b_{j} \mid a_{i} \in A, b_{j} \in B\right\} .\right.
$$

The meanings of $s_{i j}$ are as follows:

$s_{11}=\left(a_{1}, b_{1}\right)=$ (selection of the development mode, stand-alone development),

$s_{12}=\left(a_{1}, b_{2}\right)=$ (selection of the development mode, joint development),

$s_{13}=\left(a_{1}, b_{3}\right)=$ (selection of the development mode, portion outsourcing),

$s_{14}=\left(a_{1}, b_{4}\right)=$ (selection of the development mode, overall outsourcing).

The optimum target of the selection of the development mode for a software project includes five aspects, i.e. the best software quality, the cheapest development cost, the least development risk, the software development cycle satisfying client need and the process of software development in favor of the enterprise's technical storage. We can accordingly obtain the objectives set as the following element;
4. The objectives set:

$K=\left\{k_{1}, k_{2}, k_{3}, k_{4}, k_{5}\right\}=$ software quality, development cost, development risk, development cycle, technical storage $\}$.

\subsection{Data processing and weights determination}

\section{Data collection}

As introduced earlier, the essential aspects of the cobweb-based grey target model involve comparison of all areas, and selection of a relatively optimal situation. To calculate those areas, the varying degrees of satisfaction with the situations need to be evaluated and quantified, according to the objectives. Different decision-makers, with different points of view, often provide different comments on the same situations. All of the different evaluations should be systematically considered in order to achieve comprehensive and objective decision-making. Decision-makers, in connection with the OA system, include the leaders of Chana, the IT department managers and the developers. Table 1 shows the degrees of target satisfaction

Table 1. Evaluation results of decision-makers for different objectives.

\begin{tabular}{|c|c|c|c|c|c|}
\hline No. & Objectives & Situations & $\begin{array}{l}\text { Chana } \\
\text { leaders }\end{array}$ & $\begin{array}{c}\text { Dept } \\
\text { managers }\end{array}$ & Developers \\
\hline \multirow{4}{*}{1} & \multirow{4}{*}{ Software quality } & $S_{11}$ & Good & Best & Best \\
\hline & & $S_{12}$ & Bad & General & Good \\
\hline & & $S_{13}$ & Best & Bad & General \\
\hline & & $S_{14}$ & Worse & Good & Worse \\
\hline \multirow{4}{*}{2} & \multirow{4}{*}{ Development cost (unit: RMB) } & $S_{11}$ & 400,000 & 500,000 & - \\
\hline & & $S_{12}$ & 450,000 & 300,000 & - \\
\hline & & $S_{13}$ & 450,000 & 600,000 & - \\
\hline & & $S_{14}$ & 900,000 & 950,000 & - \\
\hline \multirow{4}{*}{3} & \multirow{4}{*}{ Development risk (unit: day) } & $S_{11}$ & Smaller & Big & Small \\
\hline & & $S_{12}$ & Big & Small & Smallest \\
\hline & & $S_{13}$ & Small & Smaller & Big \\
\hline & & $S_{14}$ & Biggest & Biggest & Biggest \\
\hline \multirow{4}{*}{4} & \multirow{4}{*}{ Development cycle } & $S_{11}$ & 120 & 150 & 100 \\
\hline & & $S_{12}$ & 80 & 90 & 60 \\
\hline & & $S_{13}$ & 60 & 60 & 80 \\
\hline & & $S_{14}$ & 70 & 50 & 120 \\
\hline \multirow{4}{*}{5} & \multirow{4}{*}{ Technical storage } & $S_{11}$ & Good & Good & Good \\
\hline & & $S_{12}$ & Best & Best & Best \\
\hline & & $S_{13}$ & Bad & General & General \\
\hline & & $S_{14}$ & Worse & Worse & Worse \\
\hline
\end{tabular}


via the comments of three decision-makers. Note that developers in Chana are not required to provide their opinions on development cost.

\section{Data processing: Unify effect measure}

To measure those qualitative evaluation results as displayed in Table 1, one has to convert the qualitative analysis into quantitative data. Table 2 shows the qualitative comments and their corresponding quantitative results.

As shown in Tables 1 and 2, for all the objectives, smaller numbers apparently correspond to better effect values. Hence, we can use the formula below to normalize all data into the same dimension:

$$
u_{i j}^{(k)}=\frac{\min _{i} \min _{j}\left\{r_{i j}^{(k)}\right\}}{r_{i j}^{(k)}} \times 100 .
$$

Data in Tables 1 and 2 can be normalized as numbers between 0 to 100 by Eq. (4), that is, $0 \leq u_{i j}^{(k)} \leq 100$. Table 3 shows the normalized data.

\section{Weights determination}

Generally speaking, different decision-makers often hold different standpoints with the same objective. In addition, different objectives have varying degrees of

Table 2. Qualitative analysis and their quantified data.

\begin{tabular}{clcclc}
\hline No. & $\begin{array}{c}\text { Qualitative } \\
\text { evaluation }\end{array}$ & $\begin{array}{c}\text { Quantitative } \\
\text { result }\end{array}$ & No. & $\begin{array}{l}\text { Qualitative } \\
\text { evaluation }\end{array}$ & $\begin{array}{c}\text { Quantitative } \\
\text { result }\end{array}$ \\
\hline 1 & Best & 1 & 6 & Smaller & 1 \\
2 & Good & 2 & 7 & Small & 2 \\
3 & General & 3 & 8 & General & 3 \\
4 & Bad & 4 & 9 & Big & 4 \\
5 & Worse & 5 & 10 & Biggest & 5 \\
\hline
\end{tabular}

Table 3. Quantified analytical results according to Table 1 and Eq. (3).

\begin{tabular}{|c|c|c|c|c|c|}
\hline No. & Objectives & Situations & $\begin{array}{l}\text { Chana } \\
\text { leaders }\end{array}$ & $\begin{array}{c}\text { Dept } \\
\text { managers }\end{array}$ & Developers \\
\hline \multirow{4}{*}{1} & \multirow{4}{*}{ Software quality } & $S_{11}$ & 50 & 100 & 100 \\
\hline & & $S_{12}$ & 25 & 33 & 50 \\
\hline & & $S_{13}$ & 100 & 25 & 33 \\
\hline & & $S_{14}$ & 20 & 50 & 20 \\
\hline \multirow{4}{*}{2} & \multirow{4}{*}{ Development cost } & $S_{11}$ & 75 & 60 & - \\
\hline & & $S_{12}$ & 67 & 100 & - \\
\hline & & $S_{13}$ & 67 & 50 & - \\
\hline & & $S_{14}$ & 33 & 32 & - \\
\hline \multirow{4}{*}{3} & \multirow{4}{*}{ Development risk } & $S_{11}$ & 100 & 25 & 50 \\
\hline & & $S_{12}$ & 25 & 50 & 100 \\
\hline & & $S_{13}$ & 50 & 100 & 25 \\
\hline & & $S_{14}$ & 20 & 20 & 20 \\
\hline \multirow{4}{*}{4} & \multirow{4}{*}{ Development cycle } & $S_{11}$ & 42 & 33 & 50 \\
\hline & & $S_{12}$ & 63 & 56 & 83 \\
\hline & & $S_{13}$ & 83 & 83 & 83 \\
\hline & & $S_{14}$ & 71 & 100 & 42 \\
\hline \multirow{4}{*}{5} & \multirow{4}{*}{ Technical storage } & $S_{11}$ & 20 & 20 & 20 \\
\hline & & $S_{12}$ & 100 & 100 & 100 \\
\hline & & $S_{13}$ & 25 & 33 & 33 \\
\hline & & $S_{14}$ & 20 & 20 & 20 \\
\hline
\end{tabular}


Table 4. Weights of decision-makers with respect to objectives.

\begin{tabular}{|c|c|c|c|c|c|c|}
\hline \multirow{5}{*}{ 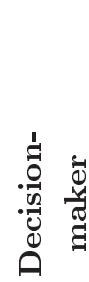 } & & \multicolumn{5}{|c|}{ Objective } \\
\hline & & $\begin{array}{c}\text { Software } \\
\text { quality }\end{array}$ & $\begin{array}{c}\text { Development } \\
\text { cost }\end{array}$ & $\begin{array}{c}\text { Development } \\
\text { risk }\end{array}$ & $\begin{array}{c}\text { Development } \\
\text { cycle }\end{array}$ & $\begin{array}{c}\text { Technical } \\
\text { storage }\end{array}$ \\
\hline & Chana leaders & 0.35 & 0.55 & 0.40 & 0.35 & 0.25 \\
\hline & Dept managers & 0.40 & 0.45 & 0.50 & 0.45 & 0.40 \\
\hline & Developers & 0.25 & - & 0.10 & 0.20 & 0.35 \\
\hline
\end{tabular}

Table 5. Weights of objectives.

\begin{tabular}{cccccc}
\hline Objective & $\begin{array}{c}\text { Software } \\
\text { quality }\end{array}$ & $\begin{array}{c}\text { Development } \\
\text { cost }\end{array}$ & $\begin{array}{c}\text { Development } \\
\text { risk }\end{array}$ & $\begin{array}{c}\text { Development } \\
\text { cycle }\end{array}$ & $\begin{array}{c}\text { Technical } \\
\text { storage }\end{array}$ \\
\hline Weight & 0.30 & 0.15 & 0.35 & 0.05 & 0.15 \\
\hline
\end{tabular}

importance in decision making. Hence, it is necessary to set the weights of decision-makers and indices prior to any decision-making. Tables 4 and 5 display the weights of decision-makers, and the weights of objectives, respectively.

\subsection{Selection of the relatively optimal situation using the cobweb areas}

1. Calculation of synthetic effect measure values:

Definition 4.1. Assume that $u_{i j}^{\left(k_{t}, p\right)}$ is the weighted effect value of the situation $s_{i j}$ with the $k_{t}$ objective and the $p$ th decision-maker, then:

$$
u_{i j}^{\left(k_{t}, p\right)}=\eta_{p}^{\prime} \times u_{i j}^{\left(k_{t}\right)},
$$

where $\eta_{p}^{\prime}$ is the weight of the $p$ th decision-maker.

The total weighted effect value of situation $s_{i j}$, with the $k$ th objective, is:

$$
u_{i j}^{\left(k_{t}\right)}=\eta_{k_{t}} \times \sum_{p=1}^{r} u_{i j}^{\left(k_{t}, p\right)},
$$

where $\eta_{k_{t}}$ is the weight of the $k_{t}$ objective.

According to Eqs. (5) and (6), we can, respectively, calculate the total effect values for the four situations. The effect values, $u_{11}^{\left(k_{1}\right)}$, of situation $s_{11}$, with objective $k_{t}(t=1,2, \cdots, 4)$, are shown below:

$$
\begin{aligned}
u_{11}^{\left(k_{1}\right)} & =\eta_{k_{1}} \times \sum_{p=1}^{3}\left(\eta_{p}^{\prime} \times u_{11}^{\left(k_{1}\right)}\right) \\
& =0.30 \times(0.35 \times 50+0.40 \times 100+0.25 \times 100) \\
& =24.75
\end{aligned}
$$$$
u_{11}^{\left(k_{2}\right)}=\eta_{k_{2}} \times \sum_{p=1}^{2}\left(\eta_{p} \times u_{11}^{\left(k_{2}\right)}\right)
$$$$
=0.15 \times(0.55 \times 75+0.45 \times 60)=10.24,
$$

$$
\begin{aligned}
u_{11}^{\left(k_{3}\right)} & =\eta_{k_{3}} \times \sum_{p=1}^{3}\left(\eta_{p}^{\prime} \times u_{11}^{\left(k_{3}\right)}\right) \\
& =0.35 \times(0.40 \times 100+0.50 \times 25+0.10 \times 50) \\
& =20.13
\end{aligned}
$$$$
\begin{aligned}
u_{11}^{\left(k_{4}\right)} & =\eta_{k_{4}} \times \sum_{p=1}^{3}\left(\eta_{p}^{\prime} \times u_{11}^{\left(k_{4}\right)}\right) \\
& =0.05 \times(0.35 \times 42+0.45 \times 33+0.20 \times 50)=1.98,
\end{aligned}
$$$$
u_{11}^{\left(k_{5}\right)}=\eta_{k_{5}} \times \sum_{p=1}^{3}\left(\eta_{p}^{\prime} \times u_{11}^{\left(k_{5}\right)}\right)
$$$$
=0.15 \times(0.25 \times 20+0.4 \times 20+0.35 \times 20)
$$$$
=3.00 \text {. }
$$

So, the total effect values of situation $s_{11}$ are:

$$
\begin{aligned}
s_{11} \mapsto u_{11} & =\left(u_{11}^{\left(k_{1}\right)}, u_{11}^{\left(k_{2}\right)}, u_{11}^{\left(k_{3}\right)}, u_{11}^{\left(k_{4}\right)}, u_{11}^{\left(k_{5}\right)}\right) \\
& =(24.75,10.24,20.13,1.98,3.00) .
\end{aligned}
$$

Similarly:

$$
\begin{aligned}
s_{12} \mapsto u_{12} & =\left(u_{12}^{\left(k_{1}\right)}, u_{12}^{\left(k_{2}\right)}, u_{12}^{\left(k_{3}\right)}, u_{12}^{\left(k_{4}\right)}, u_{12}^{\left(k_{5}\right)}\right) \\
& =(10.34,12.28,20.13,3.19,15.00), \\
s_{13} \mapsto u_{13} & =\left(u_{13}^{\left(k_{1}\right)}, u_{13}^{\left(k_{2}\right)}, u_{13}^{\left(k_{3}\right)}, u_{13}^{\left(k_{4}\right)}, u_{13}^{\left(k_{5}\right)}\right) \\
& =(23.97,7.91,25.38,4.15,4.65), \\
s_{14} \mapsto u_{14} & =\left(u_{14}^{\left(k_{1}\right)}, u_{14}^{\left(k_{2}\right)}, u_{14}^{\left(k_{3}\right)}, u_{14}^{\left(k_{4}\right)}, u_{14}^{\left(k_{5}\right)}\right) \\
& =(9.60,4.88,7.00,3.91,3.00) .
\end{aligned}
$$


2. Calculation of the cobweb area:

According to Eq. (2), we can calculate the cobweb area of situation $s_{11}$ based on its synthetic effect measure values, $v_{11}$ :

$$
\begin{aligned}
v_{11}= & \frac{1}{2} \times\left[\left|u_{11}^{\left(k_{1}\right)}-u_{o}^{\left(k_{1}\right)}\right| \times\left|u_{11}^{\left(k_{2}\right)}-u_{o}^{\left(k_{2}\right)}\right|\right. \\
& \left.+\left|u_{11}^{\left(k_{2}\right)}-u_{o}^{\left(k_{2}\right)}\right| \times\left|u_{11}^{\left(k_{3}\right)}-u_{o}^{\left(k_{3}\right)}\right|+\right] \\
& \rightarrow\left[\left|u_{11}^{(k 3)}-u_{o}^{\left(k_{3}\right)}\right| \times\left|u_{11}^{\left(k_{4}\right)}-u_{o}^{\left(k_{4}\right)}\right|\right. \\
& \left.+\left|u_{11}^{\left(k_{4}\right)}-u_{o}^{\left(k_{4}\right)}\right| \times\left|u_{11}^{\left(k_{5}\right)}-u_{o}^{\left(k_{5}\right)}\right|\right] \times \sin \frac{360^{\circ}}{t-1} \cdot(7)
\end{aligned}
$$

Take the bull's-eye, $u_{0}$, of the grey targets (the relatively optimum situation) as:

$$
\begin{aligned}
u_{0} & =\left(u_{0}^{\left(k_{1}\right)}, u_{0}^{\left(k_{2}\right)}, u_{0}^{\left(k_{3}\right)}, u_{0}^{\left(k_{4}\right)}, u_{0}^{\left(k_{5}\right)}\right) \\
& =(24.75,12.28,25.38,4.15,15.00) .
\end{aligned}
$$

Then, according to Eq. (7), the synthetic effect measure value, $v_{11}$, of situation $s_{11}$, is:

$$
\begin{aligned}
v_{11}= & \frac{1}{2} \times(|24.75-24.75| \times|10.24-12.28| \\
& +|10.24-12.28| \times 20.13-25.38 \mid+) \\
& \rightarrow(|20.13-25.38| \times|1.98-4.15| \\
& +|1.98-4.15| \times 3.00-15 \mid) \sin \frac{360^{\circ}}{5-1}, \\
v_{11}= & \frac{1}{2}(0+2.04 \times 5.25+5.25 \times 2.17+2.17 \times 12) \\
= & 24.071 .
\end{aligned}
$$

In the same way, one has:

$$
\begin{aligned}
v_{12}= & \frac{1}{2}(0+0+5.25 \times 0.96+0.96 \times 0)=2.520, \\
v_{13}= & \frac{1}{2}(0.78 \times 4.37+0+0+0)=1.704, \\
v_{14}= & \frac{1}{2}(15.15 \times 7.4+7.4 \times 18.38+18.38 \times 0.24 \\
& +0.24 \times 12)=127.707 .
\end{aligned}
$$

3. Selection of the relatively optimal situation:

Based on above calculation results, we can sort the synthetic effect measure values of the situations. The result is $v_{13}<v_{12}<v_{11}<v_{14}$. By definition of the cobweb grey target model, the smaller the cobweb area is, the better the scheme is. So, the priority of situations is formulated as:

$$
s_{13} \succ s_{12} \succ s_{11} \succ s_{14} \text {. }
$$

It is obvious that situation $s_{13}=\left(a_{1}, b_{3}\right)=$ (selection of the development mode, portion outsourcing) is a relatively optimal development mode for the Chana OA system.

\subsection{Comparison with traditional grey target model}

Here, we will apply the traditional grey target model to choose a development mode for the software project of the Chana OA system. Comparison of results with the cobweb-based grey target model are also presented in this subsection.

According to Definition 2.7, the relations shown in Box I are obtained.

According to Definition 2.8, it is obvious that $d_{13}<d_{11}<d_{12}<d_{14} \Rightarrow s_{13} \succ s_{11} \succ s_{12} \succ s_{14}$.

Table 6 shows the decision-making results of the above two models. Having compared the above models, the following conclusions can be drawn from Table 6 :

$$
d_{i j}=\sqrt{\left(u_{i j}^{\left(k_{1}\right)}-u_{o}^{\left(k_{1}\right)}\right)^{2}+\left(u_{i j}^{\left(k_{2}\right)}-u_{o}^{\left(k_{2}\right)}\right)^{2}+\cdots+\left(u_{i j}^{\left(k_{t}\right)}-u_{o}^{\left(k_{t}\right)}\right)^{2}} .
$$

One has:

$$
\begin{aligned}
& d_{11}=\sqrt{(24.75-24.75)^{2}+(10.24-12.28)^{2}+(20.13-25.38)^{2}+(1.98-4.15)^{2}+(3.00-15.00)^{2}}=13.43 \\
& d_{12}=\sqrt{(10.34-24.75)^{2}+(12.28-12.28)^{2}+(20.13-25.38)^{2}+(3.19-4.15)^{2}+(15.00-15.00)^{2}}=15.37 \\
& d_{13}=\sqrt{(23.97-24.75)^{2}+(7.91-12.28)^{2}+(25.38-25.38)^{2}+(4.15-4.15)^{2}+(4.65-15.00)^{2}}=11.26 \\
& d_{14}=\sqrt{(9.60-24.75)^{2}+(4.88-12.28)^{2}+(7.00-25.38)^{2}+(3.91-4.15)^{2}+(3.00-15.00)^{2}}=27.68 .
\end{aligned}
$$


Table 6. Comparison of decision-making results between cobweb grey target model and traditional grey target model.

\begin{tabular}{cccccc}
\hline \multirow{2}{*}{ Situation } & $\begin{array}{c}\text { Model 1: Cobweb grey } \\
\text { target model }\end{array}$ & & \multicolumn{2}{c}{$\begin{array}{c}\text { Model 2: Traditional } \\
\text { grey target model }\end{array}$} \\
\cline { 2 - 3 } \cline { 5 - 6 } & $\begin{array}{c}\text { Cobweb's area } \\
\text { coefficient }\end{array}$ & Order & & $\begin{array}{c}\text { Bull's-eye } \\
\text { distance }\end{array}$ & Order \\
\hline$s_{11}$ & $v_{11}=24.071$ & 3 & & $d_{11}=13.43$ & 2 \\
$s_{12}$ & $v_{12}=2.520$ & 2 & & $d_{12}=15.37$ & 3 \\
$s_{13}$ & $v_{13}=1.704$ & 1 & & $d_{13}=11.26$ & 1 \\
$s_{14}$ & $v_{14}=127.707$ & 4 & & $d_{14}=27.68$ & 4 \\
\hline
\end{tabular}

1. In the above two models, the relatively optimal situation is $s_{13}$, and $s_{14}$ is the most undesirable situation. This is consistent with the actual situation. As the self-defining workflow of OA is very difficult, the work cannot be independently accomplished by the Chana Group. Cooperating with other software companies is the only choice. Situation $s_{13}$ involves partial outsourcing, whereby, a complicated module can be completed by the outsourced company. On the other hand, this module is universal and has nothing to do with the specific operational details of Chana. In this case, confidential information can be safeguarded, and that is very important to a stateowned enterprise with a military background. In addition, the advantages of situation $s_{13}$ are in the development cost and development cycle. Hence, $s_{13}$ is a relatively optimal situation. Situation $s_{14}$ is overall outsourcing, and this may lead to disclosure of confidential information of the production processes of the Chana Group. Moreover, this development mode will increase development costs and is unfavorable for technical storage. So, $s_{14}$ is the most undesirable scheme in all situations;

2. The difference between the above two models in Table 6 is that $s_{12}$ is the second most optimal situation in Model 1, whereas, it is $s_{11}$ in Model 2. According to the actual conditions of the Chana Group, situation $s_{11}$ is stand-alone development. However, at present, the development task is too difficult to be achieved by employees of the Chana group themselves. Consequently, $s_{11}$ is not a desirable situation. Situation $s_{12}$ refers to joint development, whereby, software engineers of the Chana Group work with their counterparts from outsourced companies to develop complicated modules of self-defining workflow. This process can help engineers to learn advanced development technologies, and improves the technical reserves of the Chana Group. On the other hand, situation $s_{12}$ can reduce the development cycle and save development cost. According to the above analysis, situation $s_{12}$ is superior to $s_{11}$. Therefore, the decision result in Model 1 is more reasonable than that in Model 2.
3. In Model 2, through calculating the sums of squares of the differences between the decision indices of each scheme and the optimal indices, we can acquire the bull's-eye distances. The computation method, based on square operations, may result in the "amplification effect" of some secondary indices' maximums (such as the development cycle and the technical storage) or the "reduction effect" of some important indices' minimums (such as the software quality and the development risk). Because of that, the magnitude of the bull's-eye distance cannot be used to represent the soundness of a scheme. However, the calculation process of the cobweb area avoids such effects of extreme indices in Model 1. So, the decision-making result of Model 1 is more reasonable than that of Model 2.

\section{Example analysis II}

Here, we use the cobweb-based grey target model to choose the relatively optimal scheme as mentioned in Section 3.1. According to Eq. (2), the cobweb areas of situation $s_{11}$ and $s_{12}$ are shown as follows:

$$
\begin{aligned}
& v_{11}=\frac{1}{2} \times\left[\left|u_{11}^{\left(k_{1}\right)}-u_{o}^{\left(k_{1}\right)}\right| \times\left|u_{11}^{\left(k_{2}\right)}-u_{o}^{\left(k_{2}\right)}\right|\right. \\
& \left.+\left|u_{11}^{\left(k_{2}\right)}-u_{o}^{\left(k_{2}\right)}\right| \times\left|u_{11}^{\left(k_{3}\right)}-u_{o}^{\left(k_{3}\right)}\right|+\right] \\
& \rightarrow\left[\left|u_{11}^{(k 3)}-u_{o}^{\left(k_{3}\right)}\right| \times\left|u_{11}^{\left(k_{4}\right)}-u_{o}^{\left(k_{4}\right)}\right|\right. \\
& \left.+\left|u_{11}^{\left(k_{4}\right)}-u_{o}^{\left(k_{4}\right)}\right| \times\left|u_{11}^{\left(k_{5}\right)}-u_{o}^{\left(k_{5}\right)}\right|\right] \times \sin \frac{360^{\circ}}{t-1}, \\
& v_{11}=\frac{\sin 90^{\circ}}{2}[|9-10| \times|9-10|+|9-10| \times|8-10| \\
& +|8-10| \times|8-10|+|8-10| \times|6-10|]=15 .
\end{aligned}
$$

Similarly:

$$
\begin{aligned}
v_{12}= & \frac{\sin 90^{\circ}}{2}[|8-10| \times|8-10|+|8-10| \times|8-10| \\
& +|8-10| \times|8-10|+|8-10| \times|7-10|]=18 .
\end{aligned}
$$

Therefore, $v_{11}<v_{12} \Rightarrow s_{11} \succ s_{12}$. In other words, situation $s_{11}$ is superior to situation $s_{12}$. 


\section{Conclusions and future work}

The grey target decision-making model has been successfully applied to all kinds of fields. However, this method judges whether a scheme is good or bad by comparing the square sums of the differences between the evaluated indices and the optimal indices. Such "power operation" probably causes amplification or shrinkage of some extreme index values in the decisionmaking results, thus leading to model failure. For this reason, this paper proposed a novel model, called the cobweb-based grey target model, to exclude the extreme indices from the decision results. A case study in this paper shows that the present model is more reasonable than the traditional grey target decisionmaking model.

Having proposed a novel cobweb-based grey target model, our future work will be focused on the following aspects:

1. The modeling conditions of the proposed model;

2. The approaches for building a reasonable cobwebbased grey target model which includes uncertain information in the index values;

3. The methods for applying the present model to evaluate risk of an ecological system.

\section{Conflict of interests}

The authors declare there is no conflict of interests regarding the publication of this paper.

\section{Acknowledgments}

Our work was supported by the National Natural Science Foundation of China (71271226, 51375517 and 11301571) and Marie Curie International Incoming Fellowship within the 7th European Community Framework Programme (FP7-PIIF-GA-2013-629051), Project Funded by China Postdoctoral Science Foundation (2014M560712) and Chongqing Frontier and Applied Basic Research Project (cstc2014jcyjA00024). We would like to thank the anonymous referees for their constructive comments that helped to improve the clarity and completeness of this paper.

\section{References}

1. Deng, J.L. "The control problem of grey systems", System \& Control Letters, 1(5), pp. 288-294 (1982).

2. Liu, S.F., Forrest, J. and Yang, Y.J. "A brief introduction to grey systems theory", Grey Systems: Theory and Application, 2(2), pp. 89-104 (2012).

3. Wu, L.F., Liu, S.F., Yao, L.G., et al. "Grey convex relational degree and its application to evaluate regional economic sustainability", Scientia Iranica A, 20(1), pp. 44-49 (2013).
4. Wei, G.W. "Grey relational analysis model for dynamic hybrid multiple attribute decision making", Knowledge-Based Systems, 24(5), pp. 672-679 (2011).

5. Zheng, G.Z., Jing, Y.Y., Huang, H.X., et al. "Application of improved grey relational projection method to evaluate sustainable building envelope performance", Applied Energy, 87(2), pp. 710-720 (2010).

6. Egle, S., Jurgita, A. and Vladislavas, K. "Upgrading the old vernacular building to contemporary norms: multiple criteria approach", Journal of Civil Engineering and Management, 20(2), pp. 291-298 (2014).

7. Jurgis, Z., Edmundas, K.Z., Zenonas.T., et al. "Thermal insulation alternatives of historic brick buildings in Baltic Sea Region", Energy and Buildings, 78, pp. $35-42$ (2014).

8. Sadeghi, M., Hajiagha, S.H.R. and Hashemi, S.S. "A fuzzy grey goal programming approach for aggregate production planning", International Journal of Advanced Manufacturing, 64, pp. 1715-1727 (2013).

9. Dong, L.G., Daisuke, Y.G. and Masatake, N. "A greybased decision-making approach to the supplier selection problem", Mathematical and Computer Modeling of Dynamical System, 3, pp. 573-581 (2007).

10. Kung, C.Y. and Wen, K.L. "Applying grey relational analysis and grey decision-making to evaluate the relationship between company attributes and its financial performance case of venture capital enterprises in Taiwan", Decision Support Systems, 3, pp. 842-852 (2007).

11. Luo, D. and Zhang, J. "The development model of new energy vehicle in Henan Province based on the weighted grey target decision", Grey Systems: Theory and Application, 2(2), pp. 437-445 (2012).

12. Liu, S.F., Yuan, W.F. and Sheng, K.Q. "Multiattribute intelligent grey target decision mode", Control \& Decision, 25, pp. 1159-1163 (2010).

13. Wang, Z.X., Dang, Y.G. and Yang, H. "Improvements on decision method of grey target", Journal of Systems Engineering and Electronics, 31, pp. 2634-2636 (2009).

14. Hua, G.R. and Tian, W. "The decision model of grey target about mutually exclusive investment projects optimum seeking", Statistics \& Information Tribune, 20(5), pp. 36-38 (2005).

15. Zeng, B. and Liu, S.F. "Development mode's selection of software project based on twi-weighted grey target decision model", The Journal of Grey System, 22(4), pp. 367-374 (2010).

16. Dang, Y.G., Liu, S.F. and Liu, B. "Study on the multi attribute decision model of grey target based on interval number", Engineering Science, 7(8), pp. 31-35 (2005).

17. Lin, Y.H., Lee, P.C. and Ting, H.I. "Dynamic multiattribute decision making model with grey number evaluations", Expert Systems with Applications, 35(4), pp. 1638-1644 (2008). 
18. Wang, Y.H., Shi, X.J., Sun, J. H., et al. "A grey interval relational degree-based dynamic multi-attribute decision making method and its application in investment decision making", Mathematical Problems in Engineering, Article ID 607016, pp. 1-6 (2014).

19. Seyed, H.R.H., Hannan, A.M. and Shide, S.H. "A hybrid model of fuzzy goal programming and grey numbers in continuous project time, cost, and quality tradeoff", International Journal of Advanced Manufacturing, 71, pp. 117-126 (2014).

20. Zavadskas, E.K., Kaklauskas, A., Turskis, Z., et al. "Multi-attribute decision-making model by applying grey numbers", Informatica., 2, pp. 305-320 (2009).

21. Lin, Y.H., Lee, P.C. and Ting, H. "Dynamic multiattribute decision making model with grey number evaluations", Expert Systems with Applications, 35, pp. 1638-1644 (2008).

22. Wei, G.W., Wang, J.M. and Chen, J. "Potential optimality and robust optimality in multi-attribute decision analysis with incomplete information: A comparative study", Decision Support Systems, 55(3), pp. 679-684 (2013).

23. Song, J., Dang, Y.G., Wang, Z.X., et al. "New decision model of grey target with both the positive and negative clout", System Engineering-Theory \& Practice, 30, pp. 1822-1827 (2010).

24. Hu, M.L., Shen, F.F. and Chen, Y.H. "A multiattribute decision analysis method based on rough sets dealing with uncertain information", Grey Systems: Theory and Application, 2(2), pp. 324-333 (2012).

25. Liu, F.M. and Chuang, W.C. "A precaution diagnosis of financial distress via grey situation decision", The Journal of Grey System, 22, pp. 395-403 (2010).

26. Wang, Y.C. and Liu, J.G. "Unmanned system independent evaluation method", Chinese Science Bulletin, 57, pp. 1290-1299 (2012).

27. Zeng, B., Liu, S.F., Li, C., et al. "Grey target decisionmaking model of interval grey number based on cobweb area", Journal of Systems Engineering and Electronics, 35(11), pp. 8-13 (2013).

28. Liu, S.F. and Lin, Y., Grey Systems Theory and Applications, Berlin Heidelberg: Springer-Verlag (2010).
29. "Changan automobile company limited CHANGA-N", http://www.globalchangan.com/.

30. Liu, J.R., Kang, X.D. and Rao, Y.L., Software Development and Project Management, People's Post and Communication Press, Beijing (2002).

\section{Biographies}

Bo Zeng was born in 1975 . He received his $\mathrm{PhD}$ degree from Nanjing University of Aeronautics and Astronautics of China in 2012. Now, he is a Professor in Chongqing Technology and Business University of China. In recent five years, he has published about sixty papers, and more than forty of them have been indexed by Sci or Ei. Now, he is in charge of a project supported by the National Natural Science Foundation of China. His research interest is prediction and decision-making method, system modeling and simulating.

Chuan Li was born in 1975. Since he received his $\mathrm{PhD}$ degree from Chongqing University of China in 2007, he has been successively a Postdoctoral Fellow in University of Ottawa, Canada, a Research Professor in Korea University, South Korea, and a Senior Research Associate in City University of Hong Kong, China. He is currently a Professor in Chongqing Technology and Business University, China. His research interests include health maintenances for operational equipments, intelligent system theories and applications.

Si-Feng Liu was born in 1955. He is a Professor in the College of Management \& Economics of Nanjing University of Aeronautics and Astronautics. He received his $\mathrm{PhD}$ from HuaZhong University of Science \& Technology in 1997. Now, he is the Chairman of IEEE Grey System society and Vice Chairman of IEEE SMC China (Beijing) Branch. He has taken charge of an international foundation 'Marie Curie International Incoming Fellowship within the 7th European Community Framework Programme'. His research interests include Grey system theory, econometrics and energy system. 